\title{
Health-promoting behaviors in South African music students: A replication study
}

\author{
Clorinda R. Panebianco-Warrens*, Lizelle Fletcher
}

University of Pretoria, South Africa

Gunter Kreutz

Carl von Ossietzky University, Germany

*Corresponding author: Clorinda R. Panebianco-Warrens, Department of Music, University of Pretoria, Pretoria, South Africa. Email: clorinda.warrens@up.ac.za

\begin{abstract}
The study evaluated self-reported health-promoting behaviors and psychosocial well-being of undergraduate music students $(n=144)$ and was designed as an attempt to replicate and extend previous studies. The goals were (a) to differentiate those behaviors in undergraduate music students, and (b) to examine the influences of gender and instrument played.

Participants completed the health-promoting lifestyle inventory (HPLP-II), the self-efficacy (SES) and the self-regulation (SRS), scales, as well as the positive and negative affect (PANAS) scale. Results show overall deficiencies in music students' healthy habits, which is in line with previous studies. Generally, low values were found for health responsibility, physical activity, stress management and nutrition. Female students, however, achieved significantly better results for nutrition choices. Keyboard players were found to be the weakest group in health-promoting behaviors. Significant correlations were found between the subscales of the HPLP-II, self-efficacy (SES), self-regulation (SRS) and emotional state (PANAS). These results similar to other studies, moreover, support the assumption that music students' healthy behaviors generalize across different socio-cultural contexts.
\end{abstract}

Keywords: emotional state, health promotion, health responsibility, music students, self-efficacy, self-regulation

The freedom of the tertiary environment brings many new challenges for first-year students, who are faced with choices that may affect their health as well as their health-promoting behaviors (Von Ah, Ebert, Ngamvitroj, Park, \& Kang, 2004). Typical health-related problems for musicians have been increasingly investigated since the 1980s, particularly with the advent of journals devoted specifically to performing artists' health, such as the Journal of Medical Problems of Performing Artists (Brandfonbrener, 2009). It has been found that music students are at risk of developing playing-related health problems at university, although research has indicated that health problems start much earlier (Brandfonbrener, 2009; Zander, Voltmer \& Spahn, 2010). Health promotion has evolved as a key issue for education in music conservatoires (Chesky, Dawson, \& Manchester, 2006). 


\section{Health problems in musicians}

Health problems typically associated with performing musicians include pain-related musculoskeletal problems (Zander et al., 2006), performance anxiety (Kenny, 2012), symptoms of depression and anxiety, and sleep disturbance (Fishbein, Middlestadt, Ottai, Straus, \& Ellis, 1988). Spahn, Strukley, and Lehmann (2004) reported that $25 \%$ of new music students experience health problems, while Spahn, Richter, and Zschocke (2002) suggested that $68 \%-88 \%$ of music performance students had suffered health-related problems during tertiary music training, which adversely affected their performance ability. Brandfonbrener (2009) found that $79 \%$ of music students reported playing-related pain at the beginning of their studies, and Zaza (1992) established that $43 \%$ of Canadian university music students experienced playing-related health problems. Spahn, Nusseck, and Zander (2014) found that $51 \%$ of music students, tracked over a 5-year period, reported playing related health problems, indicating the necessity of specific prevention programs for student musicians.

Beside musculoskeletal problems, Zander et al. (2010) reported that psychological stresses were significantly higher in music students during the first 2 years compared with a group of medical students, and music students were more likely to seek help for physical symptoms rather than for psychological symptoms. It has been acknowledged that anxiety, as a personality trait, is common in musicians (Marchant-Haycox \& Wilson, 1992). Music students have reported debilitating levels of anxiety as a result of performance and examinations (Schneider \& Chesky, 2011), which could lead to physical and psychological health problems such as burnout and depression (Wristen \& Fountain, 2013).

Work-related health problems continue to affect professional musicians. A study assessing prevalence of pain in professional musicians showed that $86 \%$ of the musicians had reported regional pain in the previous 12 months (Leaver, Harris, \& Palmer, 2011). This study confirmed previous findings that musicians appear to experience high rates of musculoskeletal pain. Between the instrument groups, studies have pointed out ergonomic risks in string and wind instrumentalists (Kaufman-Cohen \& Ratzon, 2011, Nyman, Wiktorin, Mulder, \& Johansson, 2007; Paarup, Baelum, Holm, Manniche, \& Wedderkopp, 2011). Paarup et al. (2011) found that woodwind players showed a lower risk for musculoskeletal symptoms compared to string players, while pianists experienced a high incidence of playing-related problems compared with other instrumentalists, specifically playing-related musculoskeletal disorders (Pak \& Chesky, 2001; Roach, Marcello, Martinez, \& Anderson, 1994).

Furthermore, it has been conclusively shown that there are gender differences in performance-related health problems. Females typically show higher-frequency risk for performance-related health problems (Fishbein et al., 1988; Guptill, Zaza, \& Paul, 2000; Paarup et al., 2011; Zaza, 1992, Zaza, \& Farewell, 1997; Zetterberg, Backlund, Karlsson, Werner, \& Olsson, 1998). In spite of this, Voltmer and colleagues (2012) found that musicians, compared to the general population, reported better physical health than mental health. 


\section{Health promotion in tertiary students}

The role of health promotion, health behaviors and well-being has been studied across a wide range of contexts, including tertiary institutions (Lee \& Yuen Loke, 2005; Oleckno \& Blacconiere, 1990). Williamon and Thompson (2006) pointed out the need for more research into understanding and promoting healthy lifestyles among musicians during their formative years as well as research that highlights the specific health concerns and associated behaviors in music students. Wynn Parry (2004) asserted that musicians' health resources and health risks, respectively, are far from uniformly distributed across the world and that research, development and implementation is needed in both educational and professional contexts.

Health promotion and injury prevention programs have been successfully implemented in tertiary institutions' curricula in North America, Europe, Scandinavia, and Austral-Asia (Clark \& Lisboa, 2013, p. 163). The efficacy and success of these courses are increasingly evident (Guptill, 2008; Kreutz, Ginsborg, \& Williamon, 2008; López \& Martínez, 2013; Williamon \& Thompson, 2006). Kreutz, Ginsborg, and Williamon (2009) reported on health problems of music performance students from two conservatories in the UK: the Royal Northern College of Music in Manchester, and the Royal College of Music in London. The results suggested that music performance students tended to focus more strongly on psychosocial than physical aspects of health and particularly neglected health responsibility. Furthermore, it has been found that the role of perceived self-efficacy and self-regulation in music students' health-promoting behavior is still unclear (Kreutz et al., 2008). These findings appear important in that health-awareness in music students is not as developed as might be expected from this particular population, especially since they are facing considerable psychophysical demands with respect to their prospective careers, and the research seems not as developed as might be expected from this particular population. In fact, comparing music students with nursing and biomedical science students in a follow-up study (Ginsborg et al., 2009), the former group had lower scores on health responsibility, physical activity, and spiritual growth than the latter. However, it remains unclear whether these observations were specific to students at the respective institutions in the UK. In other words, replications of these findings, which compare music student populations in different parts of the world, are still missing.

Whereas health promotion courses are being implemented, evaluated and adapted as part of existing curricula in various countries across the world, South African universities currently lag behind compared with efforts elsewhere in the management of health-related issues for music students. There are no health promotion or injury prevention programs presented at any of the tertiary institutions offering music as a major. The present study intends to address the lack of research in this context and investigate health-promoting behaviors in undergraduate students at a tertiary institution in South Africa, while using similar measures from a previous investigation in the UK (Ginsborg, Kreutz, Thomas, \& Williamon, 2009; Kreutz, Ginsborg, \& Williamon, 2008, 2009).

\section{Aims and research questions}

The current study replicates and extends previous work by Kreutz et al. (2008, 2009). Its purpose was to explore the levels of health-promoting behaviors and other psychological variables in music students. Participants were recruited from the Department of Music at the 
University of Pretoria. The four facets of interest were the Health-Promoting lifestyle (HPLP II; Walker, Sechrist, \& Pender, 1987), Positive-Negative-Affect (PANAS; Watson, Clark, \& Tellegen, 1988), Self-efficacy (SES; Schwarzer \& Jerusalem, 1995) and Self-regulation (SRS; Schwarzer, Diehl, \& Schmitz, 1999). The subscales of the HPLP II are health responsibility, physical activity, nutrition, interpersonal relations, spiritual growth, and stress management. Importantly, the current study was designed to overcome limitations of previous research. Therefore, influences of gender differences, and vocal and instrumental tuition, as well as participation in a wider range of music education programs, were specifically addressed in the present approach. Furthermore, psychophysical demands as well as students' attitudes in relation to health issues may vary with respect to their study motivations. Finally, it should be of interest to see the extent to which previous findings could be replicated in a socio-cultural environment that is different from the UK.

The study sought to address the following main research questions: What are the healthpromoting behaviors in undergraduate music students at the University of Pretoria? Additionally, to what extent are the students' perceived health behaviors and mood states influenced by gender and instrument type (keyboard, string, vocal, and wind ${ }^{1}$ )?

\section{Method}

\section{Participants}

Undergraduate music students (first to fourth year) at the University of Pretoria, Department of Music were invited to take part in the survey, thus a non-probability purposeful sampling strategy was used.

A total of 146 music students ( 80 female and 66 male) participated in the study. Data collection took place in two sessions, 3 years apart. The reason for two data collection sessions was that the music department is small with a total of approximately 130 undergraduate students. The first data collection session yielded 74 participants and the second session included a further 72 participants. $^{2}$ The gender distribution was fairly even, 45 $\%(n=66)$ male students and $56 \%(n=80)$ female students. The ages of the respondents ranged from 18 to 37 years, with the majority of students aged between 19 and 22 years. The distribution of instruments are as follows: $42 \%(n=62)$ keyboard; 23\% $(n=33)$ vocalists; $18 \%(n=26)$ winds; and $17 \%(n=25)$ strings.

\section{Measurement instruments}

Basic demographics (age, gender) as well as information related to the study programme, ${ }^{3}$ main instrument, second instrument, and estimated number of hours practiced daily was collected. The psychometric inventories comprised of the Health Promoting Lifestyle Profile (HPLP II; Walker et al., 1995), the Self-Efficacy Expectation Scale (SES; Schwarzer \& Jerusalem, 1995), the Self-Regulation Expectation Scale (SRS; Schwarzer et al. 1999), and Positive Affect Negative Affect Schedule (PANAS; Watson et al., 1988).

The HPLP-II is an instrument providing a multidimensional assessment of health-promoting behaviors. It consists of 52 items that are rated on a 4-point Likert-type scale, anchored by 1 $=$ 'never' and $4=$ 'routinely.' The HPLP-II measures a total score for health-promoting 
behavior as well as six subscales: health responsibility, physical activity, nutrition, interpersonal relations, spiritual growth, and stress management. Health responsibility includes attending to and accepting responsibility for one's own health, and being educated about health and seeking professional assistance when necessary. Physical activity refers to keeping to regular exercise patterns, while nutritional habits include establishing meal patterns and food choices. The 'psychosocial well-being' dimension includes 'interpersonal relations,' 'spiritual growth,' and 'stress-management' subscales. Spiritual growth encompasses self-actualization and fulfillment, while interpersonal relations deal with maintenance of relationships involving a sense of intimacy and closeness. Stress management includes both recognizing the sources of stress and taking action to control stress and achieve relaxation (Lee \& Yuen Loke, 2005, p. 211).

Cronbach's alpha coefficient was calculated for the various scales as a measure of their reliability. Cronbach's $\alpha$ for the subscales ranged from .58 to .88 , demonstrating high internal consistency, with the exception of 'stress management' (.58). The stress management statement 'Accept those things in your life which you cannot change' showed a very small correlation with the items in the scale. Once this question was removed, the internal consistency improved from .53 to .58 , which is still very low. Cronbach's $\alpha$ for the other subscales of the HPLP-II are as follows: health responsibility .78; physical activity .81; nutrition .69, interpersonal relations .76, and spiritual growth .79 .

Both the SES and SRS consist of 10 self-reflective statements describing anticipated responses to situations that require coping or being adaptable to moods. These items are rated on a 4-point Likert scale ranging from $1=$ 'not at all true' to 4 'completely true.' Selfefficacy relates to managing and taking control of problems and the ability to perform selfcare behaviors, whereas self-regulation involves attaining and maintaining personal goals. Both SES and SRS showed high internal reliability with scores of .88 and .81 respectively.

The PANAS (Positive Affect Negative Affect Scale) (Watson et al., 1988) instrument is a 20item self-report measure of positive and negative feeling states. Each item is rated on a 5point Likert-type scale $(1=$ very slightly, to $5=$ extremely $)$. The PANAS has been shown to be effective at differentiating between depression and anxiety in clinical samples. Cronbach's $\alpha$ for the PANAS scales was high: .83 (positive affect) and .86 (negative affect).

\section{Procedure}

As many students did not speak English as a first language ${ }^{4}$ and the Health Promoting Lifestyle Profile II (HPLP-II) instrument is a standard questionnaire, a pilot test was conducted to determine whether there were questions that were difficult to understand or could be misinterpreted. Twenty-six questionnaires were randomly distributed on the campus to non-music undergraduate students in order to gauge whether the questions would be understood by our multilingual student population. All the items were completed without too much difficulty. However, a few minor adjustments were made to prevent misunderstandings. For example, the question 'I concentrate on pleasant thoughts' was amended to 'I concentrate on positive thoughts.'

Prior to distribution, all potential study volunteers were fully briefed with regards to the purpose and methodology of the study. Participation in the research project was voluntary and no incentives were offered. The questionnaires were administered to the undergraduate students during class times in the middle of the second semester of the 2010 and 2013 
academic years, between September and October. The middle of the term was purposely chosen because the study intended to understand usual patterns of behavior and mood states, therefore avoiding the highly stressful periods like examination time a month later, or the more rested period directly after the mid-year break. All volunteers who indicated that they would like to participate in the study completed informed consent forms in accordance with the ethical guidelines and requirements of the Research and Ethics Committee of the Faculty of Humanities at the University of Pretoria, who approved the study. Assurance was given that no student could be identified.

\section{Data analysis}

Descriptive, correlational, and inferential statistical analyses were undertaken to investigate the relationships among and between the independent and dependent measures. The General Linear Model (GLM) was used to assess students' perceived health behaviors and mood states by gender and instrument type. Statistical significance was set at the conventional 5\% level in all analyses.

\section{Results}

\section{Health-promoting behaviors}

Table 1 displays the summary statistics for the psychometric tests' subscales according to the overall scores, gender, and instrument type; the overall health-promoting behavior score (HPB) is simply the average of the six subscale scores.

\begin{tabular}{|c|c|c|c|c|c|c|c|c|c|c|c|c|c|c|c|}
\hline & & \multicolumn{2}{|c|}{$\begin{array}{l}\text { All } \\
(N=146)\end{array}$} & \multicolumn{2}{|c|}{$\begin{array}{l}\text { Females } \\
(n=80)\end{array}$} & \multicolumn{2}{|c|}{$\begin{array}{l}\text { Males } \\
(n=66)\end{array}$} & \multicolumn{2}{|c|}{$\begin{array}{l}\text { Keyboard } \\
(n=62)\end{array}$} & \multicolumn{2}{|c|}{$\begin{array}{l}\text { Stringss } \\
(n=25)\end{array}$} & \multicolumn{2}{|c|}{$\begin{array}{l}\text { Vocal } \\
(n=33)\end{array}$} & \multicolumn{2}{|c|}{$\begin{array}{l}\text { Winds } \\
(n=26)\end{array}$} \\
\hline \multicolumn{16}{|l|}{ HPLP-II } \\
\hline \multirow[t]{5}{*}{ HBP } & & 2.59 & 0.36 & 2,64 & 0.37 & 2.53 & 0.34 & 2.52 & 0.40 & 2.74 & 0.31 & 2.63 & 0.33 & 2.58 & 0.34 \\
\hline & Health responsibility & 2.01 & 0.52 & 2.12 & 0.56 & 1.88 & 0.43 & 1.97 & 0.58 & 2.13 & 0.59 & 2.02 & 0.40 & 1.99 & 0.44 \\
\hline & $\begin{array}{l}\text { Interpersonal } \\
\text { relations }\end{array}$ & 3.11 & 0.48 & 3.18 & 0.44 & 3.03 & 0.52 & 3.01 & 0.51 & 3.16 & 0.56 & 3.18 & 0.43 & 3.21 & 0.38 \\
\hline & Spiritual growth & 3.15 & 0.50 & 3.12 & 0.49 & 3.18 & 0.51 & 3.07 & 0.54 & 3.32 & 0.44 & 3.15 & 0.52 & 3.16 & 0.41 \\
\hline & Stress management & 2.47 & 0.49 & 2.44 & 0.49 & 2.50 & 0.49 & 2.35 & 0.50 & 2.67 & 0.38 & 2.49 & 0.50 & 2.52 & 0.48 \\
\hline SRS & & 3.20 & 0.64 & 3.21 & 0.62 & 3.18 & 0.66 & 3.07 & 0.58 & 3.34 & 0.45 & 3.32 & 0.78 & 3.21 & 0.68 \\
\hline SES & & 3.89 & 0.59 & 3.78 & 0.62 & 4.02 & 0.53 & 3.83 & 0.64 & 4.10 & 0.47 & 3.87 & 0.52 & 3.85 & 0.66 \\
\hline
\end{tabular}

Note $S D=$ Standard deviation HPLP-II = Health-promoting lifestyle profile; HPB = Health promoting behavior; SES = Self-eticacy scale; SRS = Self-regulation scale; PANAS = Positive and negative affect schedule. "p $<$. OS.

The overall mean score for the HPLP-II was 2.59 indicating that the levels of health promoting lifestyles amongst these music students were moderate and reported health behaviors were between 'occasional' and 'frequent.' Engagement in healthy behaviors fell between 'occasional' and 'frequent.' Table 1 shows that overall, the score for health responsibility was the lowest of all the subscales; this was also the case for the subgroups gender and instrument groups: keyboard, strings, vocal, and winds. 
Pearson's correlation coefficients were calculated to quantify the strength of the linear associations between the HPLP-II, self-regulation, self-efficacy and the PANAS positive and negative affect (Table 2). Most correlations were positive and significant implying moderate to strong associations between the measures. The exception was negative affect, which was mostly moderately negatively correlated with the other measures.

Table 2. Pearson correlations between psychometric scales.

\begin{tabular}{|c|c|c|c|c|c|c|c|c|c|c|c|}
\hline & HPB & HR & PA & NU & IR & SG & SM & SRS & SES & PosAff & NegAff \\
\hline HR & $.708^{* *}$ & 1 & & & & & & & & & \\
\hline $\mathrm{PA}$ & $.785^{\circ *}$ & $.536^{\circ}$ & 1 & & & & & & & & \\
\hline NU & $.656^{* \prime}$ & $.472^{* *}$ & $.467^{\circ \prime}$ & 1 & & & & & & & \\
\hline IR & $.616^{* \prime}$ & $.273^{* *}$ & $.287^{* \prime}$ & .154 & 1 & & & & & & \\
\hline SG & $.578^{* *}$ & .114 & $.229^{* *}$ & .162 & $.566^{* *}$ & 1 & & & & & \\
\hline SM & $.717^{*}$ & $.338^{* *}$ & $.479^{* *}$ & $.309^{* *}$ & $.394^{* *}$ & $.548^{* *}$ & 1 & & & & \\
\hline SRS & $.229^{\circ}$ & .015 & .068 & .111 & $.241^{\circ}$ & $.381^{* *}$ & $.236^{*}$ & 1 & & & \\
\hline SES & $.409^{* *}$ & .142 & .158 & $.217^{* *}$ & $.329^{* *}$ & $.597^{*}$ & $.386^{\circ}$ & $.369^{* *}$ & 1 & & \\
\hline PosAff & $.447^{* *}$ & $.207^{*}$ & $.275^{\circ}$ & $.192^{\circ}$ & $.268^{* *}$ & $.545^{\circ \prime}$ & $.444^{* *}$ & $.273^{*}$ & $.477^{* \prime}$ & 1 & \\
\hline NegAff & -.158 & $.198^{\circ}$ & .028 & .026 & -.120 & $-.284^{\circ}$ & $-.204^{\circ}$ & $-.297^{* *}$ & $-.179^{\circ}$ & $-.173^{\circ}$ & 1 \\
\hline
\end{tabular}

Note. *o Correlation is significant at the .01 level; * Correlation is significant at the .05 level.

HPLP-II = Health-promoting lifestyle profile; HPB = Health promoting behavior total score; $\mathrm{HR}=$ Health responsibility; $P A=$ Physical activity; $N U=$ Nutrition; $I R=$ Interpersonal relations; $S G=$ Spiritual growth; $S M=$ Stress management; SRS = Self-regulation scale; SES = Self-efficacy scale; PosAff = Positive affect; NegAff = Negative affect.

Table 3 summarizes the results of the GLM tests for the reported health behaviors and psychometric tests, according to gender and instrument type, as well as for the SES, SRS and PANAS instruments.

Table 3. GLM Results for overall, gender, and instrument type distributions.

\begin{tabular}{|c|c|c|c|c|c|c|}
\hline & \multicolumn{2}{|c|}{ Overall } & \multicolumn{2}{|l|}{ Gender } & \multicolumn{2}{|c|}{ Instrument type } \\
\hline & $F(7)$ & $p$ value & $F(3)$ & $p$ value & $F(3)$ & $p$ value \\
\hline \multicolumn{7}{|l|}{ HPLP-II } \\
\hline Health responsibility & 2.11 & $.047^{*}$ & 10.74 & $.001^{* 8}$ & 1.45 & .230 \\
\hline Physical activity & 1.03 & .410 & 0.85 & .359 & 1.98 & .119 \\
\hline Nutrition & 2.26 & $.012^{*}$ & 7.72 & $.006^{* *}$ & 3.39 & $.020^{*}$ \\
\hline Interpersonal relations & 1.2 & .305 & 2.87 & .092 & 1.40 & .246 \\
\hline Spiritual growth & 1.45 & .188 & 0.65 & .423 & 1.69 & .171 \\
\hline Stress management & 2.06 & .052 & 0.15 & .695 & 2.59 & .056 \\
\hline SES & 1.73 & .109 & 5.79 & $.017^{*}$ & 0.77 & .512 \\
\hline SRS & 0.84 & .554 & 0.11 & .735 & 1.34 & .265 \\
\hline PANAS positive & 1.28 & .262 & 2.16 & .143 & 0.62 & .603 \\
\hline PANAS negative & 0.74 & .639 & 0.42 & .520 & 0.73 & .533 \\
\hline
\end{tabular}

Note. HPLP-II = Health-promoting lifestyle profile; SES = Self-efficacy scale; SRS = Self-regulation scale; PANAS = Positive and negative affect schedule. ${ }^{*} p<.05 ;$ *FF $^{*}<.01$.

From the GLM procedure, statistical significant differences were found for health responsibility, nutrition and stress management on the HPLP-II (the latter is included in the discussion since $p=.052$ is a borderline value). Gender was the only factor that displayed significant differences with regards to health responsibility: males had a significantly lower 
score than females, shown in Table 1 . The nutrition subscale showed significant differences for both gender and instrument type. As with health responsibility, females had a higher score than males, albeit that both scores were quite low. Analysis of the instrument type means showed that string players had a significantly higher nutrition score than the vocal and wind subgroups. There was moderate to strong evidence $(p=.054)$ that the nutrition score was also higher than the keyboard group. None of the other groups differed from each other. Even though stress management had a $p$ value that did not meet the statistical criterion of .05 (the specified level of significance), there was moderate to strong evidence of differences among subgroups. It was found that instrument type had a $p$ value of .056, again not quite meeting the criterion. Post-hoc tests were thus not conducted. However, it was evident that string players had the highest stress management score (cf. Table 1), followed by wind players, while keyboard players had the lowest score. Low scores indicate that stress is not well managed.

\section{Emotional state, self-efficacy, and self-regulation}

No significant differences were found between scores of on any of the SRS and PANAS positive and negative measures with regard to gender and instrument type (cf. Table 3 ). The only significant difference was related to gender $(p=.017)$ for the SES scale.

\section{Comparison of findings}

Since this study is a replication of Kreutz et al. (2009), we compiled a table (Table 4) of means to compare our findings, in as far as possible, to their findings.

Table 4. Comparison of means and standard deviations (SD) between the current and Kreutz et al. (2008) study.

\begin{tabular}{|c|c|c|c|c|}
\hline \multirow[t]{2}{*}{ Measure } & \multicolumn{2}{|c|}{ Current study } & \multicolumn{2}{|c|}{ Kreutz et al. (2008) } \\
\hline & Mean & $S D$ & Mean & $S D$ \\
\hline HPB & 2.59 & 0.36 & 2.47 & 0.40 \\
\hline HResponsibility & 2.01 & 0.52 & 1.81 & 0.52 \\
\hline PhysActivity & 2.39 & 0.62 & 2.22 & 0.62 \\
\hline Nutrition & 2.57 & 0.54 & 2.71 & 0.59 \\
\hline Interpersonal & 3.11 & 0.48 & 2.95 & 0.54 \\
\hline Spiritual & 3.15 & 0.50 & 2.88 & 0.56 \\
\hline StressM & 2.47 & 0.49 & 2.26 & 0.49 \\
\hline SRS & 3.20 & 0.64 & 3.18 & 0.57 \\
\hline SES & 3.89 & 0.59 & 3.57 & 0.63 \\
\hline PANASpos & 3.51 & 0.74 & 3.43 & 0.75 \\
\hline PANASneg & 2.40 & 0.81 & 2.09 & 0.73 \\
\hline
\end{tabular}

Note. HPB = Health-promoting behavior; SRS = Self-regulation scale; SES = Self-efficacy scale; PANAS = Positive and negative affect schedule.

It is clear from Table 4 that very similar trends are evident. The results of the HPLP-II show that health responsibility was scored the lowest of the subscales in both studies, and interpersonal relations and spiritual growth were scored highest. Furthermore, with the exception of the PANAS negative, in which our students showed a higher score than Kreutz et al. (2009), all the scores between the other scales were similar. The higher score for 
negative affect suggested that our students did not experience negative affect as acutely as the students in the Kreutz et al.'s (2009) study.

\section{Discussion}

This study focused on self-reported health-promoting behaviors and mood states in undergraduate music students by partially replicating previous approaches (Kreutz et al., 2008, 2009) in a different setting. The main research questions addressed health-promoting behaviors in undergraduate music students at the University of Pretoria.

Overall, health-promoting behavior (HPB) was strongly correlated with positive affect and self-efficacy, which were in turn correlated with spiritual growth and with each other; whilst the latter was correlated with interpersonal relations, thus demonstrating the intercorrelated nature of the subscales. This finding is similar to that observed in Kreutz et al. $(2008,2009)$. Furthermore, health responsibility was positively correlated with physical activity and nutrition, which were also correlated with each other.

Our results suggest that the overall health behaviors of music students in our sample were generally not favorable, thus confirming and extending previous studies (Ginsborg et al., 2009; Kreutz et al., 2008). In particular, as found by others, the current result established moderate levels of health behaviors among music students in several health-promotion components. Specifically, low scores were found for health responsibility, physical activity, stress management and nutrition, whereas the highest scores were reported for the scales measuring psychosocial behavior, namely interpersonal relations, spiritual growth, selfefficacy and self-regulation. The measures of health responsibility presented the lowest score and self-efficacy the highest. As for the six subscales of the HPLP-II, students scored highest in the self-efficacy subscale, which is consistent with findings from various studies (Ginsborg et al., 2009; Kreutz et al., 2008, Peker \& Bermek, 2011).

The present study revealed that female students had better health-promoting behavior and had significantly higher scores for nutrition choices than male students had. Again, these findings are inconsistent with other studies that found only slightly higher health-promoting behaviors in female students (Lee \& Yuen Loke, 2005; Hong, Sermisi, \& Keiwkarna, 2007; Kreutz et al., 2008). Specifically, female music students rated higher on a range of other items indicating healthy diets. This is not too surprising, as women across different cultures were shown to have significantly stronger beliefs in the importance of nutrition than males (Wardle, Haase, \& Steptoe, 2004).

This study showed that female students had lower scores for stress management than male students had, possibly indicating a higher level of experienced anxiety, which concurs with the findings of Zander et al. (2010) who suggest that female students suffer more from psychological symptoms compared to male students. This result correlates with previous studies that have indicated that female musicians typically show higher frequency risk for performance-related health problems (Fishbein et al., 1988; Guptill et al., 2000; Zaza, 1992, Zaza et al., 1997; Zetterberg et al., 1998). Interestingly, our study revealed that male students had significantly higher self-efficacy scores than female students. This finding corresponds with previous studies that also found male music students more self-efficacious than females (Zimmerman, \& Martinez-Pons, 1990, see Nielsen, 2004). 
Keyboard players reported significantly lower scores than other instrumentalists on the four sub-scales health responsibility, physical activity, interpersonal relations and stress management. Subsequently, the overall health promoting behavior score was the lowest of the instrument types. Furthermore, keyboard players were not as positive as other instrumentalists, as seen in the low positive-affect score. This finding could be explained by the fact that keyboard instrumentalists typically start lessons at a younger age on average and possibly accumulate more time practicing than other instrumentalists (Jørgensen, 2001). Although we can only speculate about the origin of these group differences as practicerelated or not, it should be worthwhile to investigate healthy lifestyles in far more detail in the future at the level of musical instruments and individual differences. For example, it is presently unknown whether and how the pressures of competition vary among and between instrumentalists and whether such variation could have positive or negative effects on music students' healthy lifestyles.

The results of the health responsibility subscale are consistent with previous work in suggesting that students do not often report unusual signs or symptoms to a doctor, nor do they discuss or ask enough questions in order to understand problems, should they arise. These music students probably did not seek guidance or counselling when necessary. It may be that music students generally feel little need yet to adapt their lifestyles to the demands of their future profession.

The component of healthy lifestyles that scored second lowest is physical activity. This is not surprising since music students are probably not as active as they should be, given the time music courses demand. As reported by Kreutz et al. (2009, p. 54), less than $30 \%$ of the British population above 15 years of age were classified as sufficiently physically active (Cavil, Kahlmeier, \& Racioppi, 2006, p. 9; see Kreutz et al., 2009, p. 54 for details). In South Africa, only $30 \%$ of men and $24 \%$ of women report sufficient levels of daily physical activity. Similarly, the SA Youth Risk Behaviour Study found that more than one third of adolescents report inadequate physical activity (Kolbe-Alexander, Bull, \& Lambert, 2012). Whether macro- and micro-environmental constraints, e.g. urban environment and situational settings, could hinder higher levels of individual physical activity, is currently unknown. The fact that keyboard players engage in even less physical activity than the other instrumentalists suggests, however, that environmental factors might not play a dominant role.

Our results further indicate that the participants did not manage stress well. This was evident in that they scored low on items related to taking enough time for relaxation, knowing and using stress-reducing techniques, practicing stress control, or pacing themselves with respect to the demands of their studies. This result is worrying given that the scores reflect the behaviors of all music students over the 4 years of study, not only performance majors as seen in previous studies. The association between keyboard players and stress in this study shows that keyboard players experience stress more acutely than other instrumentalists, which possibly suggests that lack of physical activity and stress could be correlated. High stress levels may account for low scores for health responsibility because they may reduce students' intention and implementation of health-promoting behaviors. Stress could also be an indication of general anxiety and performance anxiety. However, our study did not focus on the nature of stress per se, and this aspect of the study needs further investigation. The finding nevertheless needs to be taken seriously because the relationship between psychological stress and musculoskeletal pain has been found in various studies (Middlestat \& Fishbein, 1988; Spahn et al., 2004) indicating the potential risk for music students of developing performance-related injuries. We speculate that the low Cronbach score for stress 
management on the measures used in this study could be an indication that the current research instrument does not measure stress adequately.

Measures of positive affect were high, and were associated with the other high scores for psychosocial behavior. Positive and negative affect scores were both in a similar range of values found in other studies. The general perceived self-efficacy score appears high with an overall value of 3.89. The score is consistent with other studies that also revealed high scores for perceived self-efficacy. Furthermore, no statistical differences were found between the groups for the SES and SRS subscales.

Similar to Kreutz et al. (2009, p. 57), positive affect was found to be associated with healthy behavior and had a strong association with spiritual growth and self-efficacy. Correlations between positive affect and the other subscales were all positive, and possibly suggest that positive feeling and self-efficacy enhance a healthy lifestyle. Kreutz et al. (2009, p. 57) posited that students' high levels of positive affect and self-efficacy may compensate to an extent for their relatively low levels of healthy behaviors. These findings may confer with the fact that positive self-beliefs play an important role in maintaining healthy behaviors and that, as Bandura (1997) suggests, there is a symbiotic relationship between self-beliefs, emotions, and behaviors.

The study had a number of limitations that could be addressed. The size of the sample may have hindered the power of the current study to detect underlying difference between instrumental and vocal groups. Firm conclusions could not be drawn as a result. A follow-up study with students from other universities would increase the sample significantly, as would a comparative study with non-music major undergraduate students. A longitudinal study amongst music students to monitor variables could yield interesting results. An in-depth look at the musculoskeletal problems between the instrumentalists and vocal students could be explored.

Clearly, further investigation into determinants of perceived daily stressors as well as prevalence of levels of music performance anxiety are needed to explore the exact nature of stressors and the effects of healthy lifestyles on modulating those. Furthermore, music students need more systematic advice to advance their healthy habits, balanced diet, regular exercise and efficient stress-management skills. However, it is not clear how this advice can be promoted with as little interference with the general curriculum as possible, and what such a health promotion program would contribute to health prevention in both the shorter and longer terms.

In conclusion, this study evaluated self-reported health-promoting behaviors and psychosocial well-being of undergraduate music students at the University of Pretoria, and identified differences between male and female students, and instrumental players. It offers an insight into health-related issues for undergraduate music students and has implications for the health management and education of health-related concerns.

The goal of the study was to investigate and gain insight into current health behaviors of music students and promote healthy behaviors and life-style choices so that they becomes an integral part of lifestyle. It is evident that music students at the Department of Music at the University of Pretoria have moderate health-promoting behaviors. Students' perceived health behaviors and mood states are not overtly influenced by gender and the nature of their study program, although keyboard players do report significant differences. However, the findings 
of this study point to a need for deeper investigation into health-related, musculoskeletal problems and stress-related issues amongst music students.

It is encouraging to note that in spite of low scores in health responsibility, physical activity, stress management, and nutrition, music students generally report positive psychosocial behavior in higher scores for spiritual growth, interpersonal relations, self-efficacy, and selfregulation. Fortunately, South African music students report self-efficacy as the highest scores, similar to other studies that have found self-efficacy as among the most important predictors of university students' health-promoting behaviors (Hong et al., 2007; Kim, 2006; Kreutz et al., 2009; Von Ah et al., 2004). Most notably, the findings of this study support the assumption that music students' healthy behaviors are similar across different socio-cultural contexts.

While health promotion is ultimately the responsibility of the individual, there remains a need for tertiary educational institutions to provide healthy and safe environments for their clients (Kreutz et al. 2009, p. 48; cf. Chesky et al., 2006). In a similar vein, Nagel (2009) advocates the establishment of psychological and physical interdisciplinary programs and courses in the curriculum as important aspects of healthy music programs.

There are currently no comprehensive health promoting and injury prevention courses available to music students at tertiary institutions in South Africa. To plan appropriate preventive measures for our context, the results of this study could be a good starting point for understanding health behaviors of South African music students, which in turn could serve as an introduction to much needed discussion around student musicians' health-related issues. There can be little doubt that these students might benefit from institutions establishing and incorporating relevant programs into their curriculum to address the challenges of music practice and performance, and to promote healthy lifestyles of evolving artists.

\section{Funding}

This research received no specific grant from any funding agency in the public, commercial, or not-for-profit sectors.

\section{Notes}

1. Instruments in the 'Keyboard' category include piano and organ; 'Strings' include violin, viola, cello, double bass, and guitar; and 'Winds' consist of woodwind and brass instrumentalists.

2. Of the students, $28 \%(n=41)$ were in their first year of study, $32 \%(n=47)$ were second-year students, $25 \%(n=37)$ were third-year students, and, $14 \%(n=21)$ were fourth-year students. The reason for the small number of fourth-year students is that the data collection was taken 3 years apart, in other words, the second data collection session included the new intake of first-, second- and third-year students. The current fourth-year students were in their first year at the time of the first data collection. 
3. Music students at the University of Pretoria have a choice of two music courses BMus (4-year degree) and BAMus (3-year degree).

4. South Africa has 11 official languages. The University of Pretoria uses primarily two official languages; namely Afrikaans and English. Tuition in other official languages is available provided there is demand and it is economically justifiable.

\section{References}

Bandura A. (1997). Self-efficacy: The exercise of control. New York, NY: W.H. Freeman.

Brandfonbrener A. G. (2009). History of playing-related pain in 330 university freshman music students. Medical Problems of Performing Artists, 24(3), 117-119.

Cavill N., Kahlmeier S., Racioppi F. (2006). Physical activity and health in Europe:

Evidence for action. Copenhagen: WHO publications.

Chesky K. S., Dawson W. J., Manchester R. (2006). Health promotion in schools of music: Initial recommendations for schools of music. Medical Problems of Performing Artists, 21(3), 142-144.

Clark T., Lisboa T. (2013). Training for sustained performance: Moving toward long-term musician development. Medical Problems of Performing Artists, 28(3), 159-168.

Fishbein M., Middlestadt S., Ottai V., Straus S., Ellis A. (1988). Medical problems among ICSOM musicians: Overview of a national survey. Medical Problems of Performing Artists, $3(3), 1-8$.

Ginsborg J., Kreutz G., Thomas M., Williamon A. (2009). Healthy behaviours in music and non-music performance students. Health Education, 100(3), 242-258.

Guptill C. (2008). Musicians' health: Applying the ICF framework in research. Disability and Rehabilitation, 30(12-13), 970-977.

Guptill C., Zaza C., Paul S. (2000). An occupational study of physical playing-related injuries in college music students. Medical Problems of Performing Artists, 15, 86-90.

Hong J. F., Sermisi S., Keiwkarna B. (2007). Health-promoting life-style of nursing students in Mahidol University. Journal of Public Health Development, 5(1), 27-40.

Jørgensen H. (2001). Instrumental learning: Is an early start a key to success? British Journal of Music Education, 18(3), 227-239.

Kaufman-Cohen Y., Ratzon N. Z. (2011). Correlation between risk factors and musculoskeletal disorders among classical musicians. Occupational Medicine, 61, 90-95.

Kenny D. (2012). The psychology of music performance anxiety. Oxford, UK: Oxford University Press. 
Kim H. K. (2006). Factors influencing health-promoting behaviours of university students in Pender's model. Korean Journal of Women Health Nursing, 12(2), 132-41.

Kolbe-Alexander T. L., Bull F., Lambert E. V. (2012). Physical activity advocacy and promotion: The South African experience. South African Journal of Sports Medicine, 24(4), $112-115$.

Kreutz G., Ginsborg J., Williamon A. (2008). Music students' health problems and healthpromoting behaviours. Medical Problems of Performing Artists, 23(1), 3-11.

Kreutz G., Ginsborg J., Williamon A. (2009). Health-promoting behaviours in conservatoire students. Psychology of Music, 37(1), 47-60.

Leaver R., Harris E. C., Palmer K. T. (2011). Musculoskeletal pain in elite professional musicians from British symphony orchestras. Occupation Medicine, 61, 549-555.

Lee R., Yuen Loke A. (2005). Health-promoting behaviours and psychosocial well-being of university students in Hong Kong. Public Health Nursing, 22(3), 209-220.

López T. M., Martínez J. F. (2013). Strategies to promote health and prevent musculoskeletal injuries in students from the high conservatory of music of Salamanca, Spain. Medical Problems of Performing Artists, 18(2), 100-106.

Marchant-Haycox S. E., Wilson G. D. (1992). Personality and stress in performing artists. Personality and Individual Differences, 13, 1060-1068.

Middlestadt S., Fishbein M. (1988). Health and occupational correlates of perceived occupational stress in symphony orchestra musicians. Journal of Occupational Medicine, 30(9), 687-692.

Nagel J. J. 2009. How to destroy creativity in music students: The need for emotional and psychological support services in music school. Medical Problems of Performing Artists, 24(1), 15-17.

Nielsen S. G. (2004). Strategies and self-efficacy beliefs in instrumental and vocal individual practice: A study of students in higher music education. Psychology of Music, 32(4), 418431.

Nyman T., Wiktorin C., Mulder M., Johansson Y. L. (2007). Work postures and neckshoulder pain among orchestra musicians. American Journal of Industrial Medicine, 50(5), 370-376.

Oleckno W., Blacconiere M. (1990). Wellness of college students and differences by gender, race, and class standing. College Student Journal, 24(4), 421-429.

Paarup H. M., Baelum J., Holm J. W., Manniche C., Wedderkopp N. (2011). Prevalence and consequences of musculoskeletal symptoms in symphony orchestra musicians vary by gender: A cross-sectional study. BMC Musculoskeletal Disorders, 12, 223. 
Pak C.H., Chesky K. (2001). Prevalence of hand, finger and wrist musculoskeletal problems in keyboard intrumentalists. Keyboard instrumentalists: The University of North Texan Musician, Medical Problems of Performing Artists, 16(2), 17-23.

Peker K., Bermek G. (2011). Predictors of health-promoting behaviours among freshman dental students at Istanbul University. Journal of Dental Education, 75(3), 423-420.

Roach K. E., Marcelo P. T., Martinez M. S., Anderson M. S. (1994). Musculoskeletal pain in student instrumentalists: A comparison with the general student population. Medical Problems of Performing Artists, 9(4), 125-130.

Schneider E., Chesky K. (2011). Social support and performance anxiety of college music students. Medical Problems of Performing Artists, 26(1), 157-163.

Schwarzer R., Jerusalem M. (1995). Generalised self-efficacy scale. In Weinman J., Wright S., Johnston M. (Eds), Measures in health psychology: A user's portfolio. Causal and control beliefs (pp. 35-37). Windsor, UK: NFER-NELSON.

Schwarzer R., Diehl M., Schmitz G. S. (1999). The self-regulation scale. Berlin, Germany: Freie Universität.

Spahn C., Nusseck N., Zander M. (2014). Long-term analysis of health status and preventive behaviour in music students across an entire university program. Medical Problems of Performing Artists, 29(1), 8-15.

Spahn C., Richter B., Zschocke I. (2002). Health attitudes, preventive behaviour, and playing-related health problems among music students. Medical Problems of Performing Artists, 17(1), 22-28.

Spahn C., Strukely S., Lehmann A. (2004). Health conditions, attitudes toward study, and attitudes toward health at the beginning of university study: Music students in comparison with other student populations. Medical Problem of Performing Artists, 19(1), 26-44.

Voltmer E., Zander M., Fischer J. E., Kudielka B., Richter B., Spahn C. (2012). Medical Problems of Performing Artists, 27(1), 9-14.

Von Ah D., Ebert S., Ngamvitroj A., Part N., Kang D. H. (2005). Predictors of health behaviours in college students. Journal of Advanced Nursing, 48(5), 463-474.

Walker S., Sechrist K., Pender N. (1987). The health-promoting lifestyle profile: Development and psychometric characteristics. Nursing Research, 36(2), 78-81.

Wardle J., Haase A. M., Steptoe A. (2004). Gender differences in food choices: The contribution of health beliefs and dieting. Annals of Behavioural Medicine, 27(2), 107-116.

Watson D., Clark L. A., Tellegen A. (1988). Development and validation of brief measures of positive and negative affect: The PANAS Scales. Journal of Personality and Social Psychology, 54(6), 1063-1070. 
Williamon A., Thompson S. (2006). Awareness and incidence of health problems among conservatoire students, Psychology of Music, 34(4), 411-430.

Wristen B. G., Fountain S. E. (2013). Relationships between depression, anxiety and pain in a group of university music students. Medical Problems of Performing Artists, 28(3), 152-158.

Wynn Parry C. B. (2004). Managing the physical demands of musical performance. In Williamon A. (Ed.), Musical Excellence Strategies and techniques to enhance performance (pp. 41-60). Oxford, UK: Oxford University Press.

Zander M. R, Voltmer E., Spahn C. (2010). Health promotion and prevention in higher music education. Medical Problems of Performing Artists, 25(2), 54-65.

Zaza C. (1992). Playing-related health problems at a Canadian music school. Medical Problems of Performing Artists, 7, 48-51.

Zaza C., Farewell V.T. (1997). Musicians' playing related musculoskeletal disorders: An examination of risk factors. American Journal of Industrial Medicine, 32, 292-300.

Zetterberg C., Backlund H., Karlsson J., Werner H., Olsson L. (1998). Musculoskeletal problems among male and female music students. Medical Problems of Performing Artists, 13(4), 160-166.

Zimmermann B.J., Martinez-Pons M. (1990). Student differences in self-regulated learning: Relating grade, sex, and giftedness to self-efficacy and strategy use. Journal of Educational Psychology, 82(1), 51-59. 